\title{
Public-health impact of accelerated measles control in the WHO African Region 2000-03
}

\author{
M Otten, R Kezaala, A Fall, B Masresha, R Martin, L Cairns, R Eggers, R Biellik, M Grabowsky, P Strebel, J-M Okwo-Bele, D Nshimirimana
}

\section{Summary}

Lancet 2005; 366: 832-39

See Comment page 787

Global Measles Branch, Global Immunization Division, Centers for Disease Control and Prevention, Atlanta, GA, USA (M Otten MD, L Cairns MD, P Strebel MB); WHO Regional Office for Africa, Harare, Zimbabwe (R Kezaala MB, B Masresha MD, R Biellik DrPH, D Nshimirimana MD); WHO Regional Office for Africa Abidjan, Côte d'Ivoire (A Fall MD); WHO Regional Office for Africa, Nairobi, Kenya (R Martin PhD, R Eggers MMed); American Red Cross, Washington DC, USA (M Grabowsky MD); Vaccines and Biologicals, WHO, Geneva Switzerland

(J-M Okwo-Bele MD)

Correspondence to: Dr M Otten, Centers for Disease Control and

Prevention, MS E05, 1600 Clifton, Atlanta, GA 30333, USA motten@cdc.gov

Background In 2000, the WHO African Region adopted a plan to accelerate efforts to lower measles mortality with the goal of decreasing the number of measles deaths to near zero. By June, 2003, 19 African countries had completed measles supplemental immunisation activities (SIA) in children aged 9 months to 14 years as part of a comprehensive measles-control strategy. We assessed the public-health impact of these control measures by use of available surveillance data.

Methods We calculated percentage decline in reported measles cases during 1-2 years after SIA, compared with 6 years before SIA. On the basis of data from 13 of the 19 countries, we assumed that the percentage decline in measles deaths equalled that in measles cases. We also examined data on routine and SIA measles vaccine coverage, measles case-based surveillance, and suspected measles outbreaks.

Findings Between 2000 and June, 2003, 82.1 million children were targeted for vaccination during initial SIA in 12 countries and follow-up SIA in seven countries. The average decline in the number of reported measles cases was 91\%. In 17 of the 19 countries, measles case-based surveillance confirmed that transmission of measles virus, and therefore measles deaths, had been reduced to low or very low rates. The total estimated number of deaths averted in the year 2003 was 90 043. Between 2000 and 2003 in the African Region as a whole, we estimated that the percentage decline in annual measles deaths was around 20\% (90 043 of 454000$)$.

Interpretation The burden of measles in sub-Saharan Africa can be reduced to very low levels by means of appropriate strategies, resources, and personnel.

\section{Introduction}

Measles is an important cause of child mortality in subSaharan Africa. Estimates of the annual number of measles deaths in the WHO African Region (which now includes all countries south of the Sahara except Somalia and Djibouti; Algeria is included, but Sudan is not) made by different methods have been in the same range: 445000 in $1998,{ }^{1} 482000$ in $1999,{ }^{2}$ and 452000 in $2000 .{ }^{3}$ The WHO reported that in 2000 sub-Saharan Africa had $58 \%$ of worldwide measles deaths.

In 1996, seven countries in southern Africa (Botswana, Lesotho, Malawi, Namibia, South Africa, Swaziland, and Zimbabwe) began a measles-elimination initiative based on the successful strategy used in the Americas. ${ }^{4,5}$ In 1998, the WHO African Region Office drafted a plan of action to decrease the number of measles deaths to near zero in response to the measles mortality burden in the rest of the African countries. This plan emphasised four components: improved routine immunisation, a second opportunity for measles vaccination during supplemental immunisation activities (SIA), measles case management, and measles surveillance. Owing to shortage of funding and potential adverse effects on the polio-eradication programme, supplemental immunisations in a limited age-group (children aged 9 months to 4 years) were given in seven countries for 3 years from December, 1998, to 2001. ${ }^{1}$ Because surveillance data indicated that targeting of this age-group did not have the desired effect on the burden of disease from measles, ${ }^{1}$ in December, 2001, SIA began to target children aged 9 months to 14 years in eastern and western African countries. In 2001, a joint WHO and UNICEF global plan for measles mortality was formulated, ${ }^{6}$ with one of the four strategies being provision of a second opportunity for measles immunisation for all children through SIA or routine immunisation systems. The target for the overall measles-mortality reduction plan was a $50 \%$ decrease in the number of measles deaths by 2005 compared with 1999.

A new partnership supporting measles-mortality reduction in Africa, the Measles Initiative, started in 2001. Initial partners were the American Red Cross, the WHO, the US Centers for Disease Control and Prevention, the United Nations Foundation, and UNICEF. Subsequently, the Canadian International Development Agency, the Bill and Melinda Gates Foundation, the Church of Latterday Saints, and the Global Alliance for Vaccines and Children (GAVI) have joined the partnership. Partnership funds permitted the financing of SIA in the extended age-group. With funding primarily from the Measles Initiative, 12 African countries undertook SIA in children aged 9 months to 14 years from December, 2001, to June, 2003. In addition, seven southern African countries carried out their first round of follow-up SIA in children aged 9 months to 4 years from 2000 to 2003 mainly using national funds. 
Starting in 1999, routine immunisation services began to improve in several African countries, owing to better resources, more staff, and attention to immunisation because of the polio-eradication and measles programmes, and a focus on improving routine immunisation by the new GAVI.

We report on the estimated effect of these accelerated control activities on the numbers of measles cases and deaths, and thus monitor progress towards the goal of lowering measles mortality. We used three sources of epidemiological data to assess the effect of accelerated control efforts on the burden of measles: aggregate routine surveillance data, case-based surveillance data, and information from outbreak investigations.

\section{Methods \\ Aggregate routine surveillance data}

All African countries include notification of measles cases in their routine surveillance or health-information systems. The national aggregate number of cases is reported each year to WHO, which maintains a global database with this information, with data starting in 1980. ${ }^{\text {? }}$

For 19 African countries that undertook measles SIA between 2000 and June, 2003 (table 1), we compared the average annual number of reported measles cases in the 6 years before the start of SIA with the average annual number of reported measles cases after the SIA. For the
12 countries that undertook SIA from December, 2001 to June, 2003 (Benin, Burkina Faso, Burundi, Cameroon, Ghana, Kenya, Mali, Rwanda, Senegal, Tanzania, Togo, Zambia), we used 1996-2001 as the preSIA years. Data were missing for 4 (2\%) of 175 countryyears. We imputed the number of cases for the missing years by using the average of the previous 6 years. In seven of the 12 countries (Benin, Burundi, Cameroon, Ghana, Kenya, Senegal, Tanzania), we used 2003 as the post-SIA comparison year. For Burkina Faso, Togo, and Mali (the only countries with 2 complete years after nationwide catch-up SIA), we averaged nationwide data for 2002 and 2003. For Rwanda (SIA in February, 2003), we used data from March, 2003, to February, 2004, and for Zambia (SIA in June, 2003), we used data from July, 2003, to June, 2004. For the seven southern African countries (table 1), we used $1990-95$ as the pre-SIA comparison period and all available data for the years after the initial SIA until 2003 (ie, 6 years of data for Namibia and South Africa; 5 years for Malawi, Botswana, and Zimbabwe; 4 years for Swaziland; and 3 years for Lesotho) as the post-SIA comparison period.

To estimate the number of measles deaths averted in 2003 in each of the 19 countries, we assumed that SIA resulted in the same percentage reduction in measles deaths as was observed for measles cases. This assumption was based on the following experience in 13 of the 19 countries. After the initial SIA in the seven

\begin{tabular}{|c|c|c|c|c|c|}
\hline Country & Dates of SIA & $\begin{array}{l}\text { Children } 9 \text { months } \\
\text { to } 14 \text { years covered (\%) }\end{array}$ & $\begin{array}{l}\text { Target number } \\
\text { of children (millions) }\end{array}$ & $\begin{array}{l}\text { SIA coverage } \\
(\%)^{*}\end{array}$ & $\begin{array}{l}\text { Routine immunisation } \\
\text { coverage, } 2000\end{array}$ \\
\hline \multicolumn{6}{|c|}{ Countries with initial SIA in children aged 9 months to 14 years } \\
\hline \multirow[t]{2}{*}{ Benin } & December, 2001 & 35 & 0.9 & $98(A)$ & 85 \\
\hline & December, 2002 & 65 & $2 \cdot 0$ & $105(A)$ & .. \\
\hline Burkina Faso & December, 2001 & Nationwide & $5 \cdot 2$ & $97(S)$ & 59 \\
\hline Burundi & June, 2002 & Nationwide & $3 \cdot 2$ & $90(A)$ & 57 \\
\hline \multirow[t]{2}{*}{ Cameroon } & December, 2001 & 34 & $2 \cdot 8$ & $93(\mathrm{~A})$ & 49 \\
\hline & December, 2002 & 66 & $5 \cdot 1$ & $90(A)$ & .. \\
\hline \multirow[t]{2}{*}{ Ghana } & December, 2001 & 9 & 0.8 & $98(S)$ & 84 \\
\hline & December, 2002 & 91 & $7 \cdot 7$ & $102(\mathrm{~A})$ & .. \\
\hline Kenya & June, 2002 & Nationwide & $13 \cdot 6$ & $94(S)$ & 46 \\
\hline Mali & December, 2001 & Nationwide & $5 \cdot 1$ & $99(S)$ & 57 \\
\hline Rwanda $†$ & February, 2003 & Nationwide & $3 \cdot 1$ & $96(S)$ & 57 \\
\hline Senegal & January, 2003 & Nationwide & $5 \cdot 0$ & $98(A)$ & 48 \\
\hline \multirow[t]{2}{*}{ Tanzania } & September, 2001 & 33 & $3 \cdot 7$ & $104(A)$ & 78 \\
\hline & September, 2002 $\ddagger$ & 67 & $7 \cdot 0$ & $97(A)$ & .. \\
\hline Togo & December, 2001 & Nationwide & $2 \cdot 4$ & $95(S)$ & 43 \\
\hline \multirow[t]{2}{*}{ Zambia } & October, 2002 & 11 & 0.7 & $110(\mathrm{~A})$ & 70 \\
\hline & June, 2003 & 89 & $5 \cdot 0$ & $108(A)$ & .. \\
\hline \multicolumn{6}{|c|}{ Southern African countries undertaking follow-up campaigns in children aged 9 months to 4 years } \\
\hline Botswana & May-June, 2001 & Nationwide & $0 \cdot 3$ & $85(A)$ & 79 \\
\hline Lesotho & April-July, 2003 & Nationwide & $0 \cdot 2$ & $87(\mathrm{~A})$ & 63 \\
\hline Malawi & August, 2002 & Nationwide & $1 \cdot 5$ & $95(A)$ & 81 \\
\hline \multirow[t]{2}{*}{ Namibia } & June, 2000 & Nationwide & $0 \cdot 3$ & $89(A)$ & 69 \\
\hline & June, 2003 & Nationwide & $0 \cdot 3$ & $89(A)$ & .. \\
\hline South Africa & May-June, 2000 & Nationwide & 4.5 & $91(\mathrm{~A})$ & 95 \\
\hline Swaziland & June, 2002 & Nationwide & 0.2 & $86(A)$ & 80 \\
\hline Zimbabwe & July, 2002 & Nationwide & 1.8 & $85(A)$ & 70 \\
\hline
\end{tabular}


southern African countries, the number of reported measles cases declined by $99.8 \%$ and the number of reported measles deaths by $100 \% .^{5}$ After similar SIA in Mali, Burkina Faso, and Togo, the number of reported measles cases declined by $91.0 \%$ and the number of reported deaths by $84.0 \%{ }^{8}$ After SIA in Benin and Cameroon, the number of reported measles cases declined by $97.0 \%$ and the number of measles deaths by 96.0\% (unpublished data, WHO African Regional Office). In Zambia, the number of reported cases declined by $87 \%$ and the number of deaths by $99 \% .{ }^{9}$

Because there are few vital-event systems registering a high proportion of deaths in Africa, we used previously published estimates of the number of measles deaths before the SIA (1998 baseline year). ${ }^{1}$ We chose 1998 as the baseline year because it was the last year before measles SIA began in non-southern African countries.

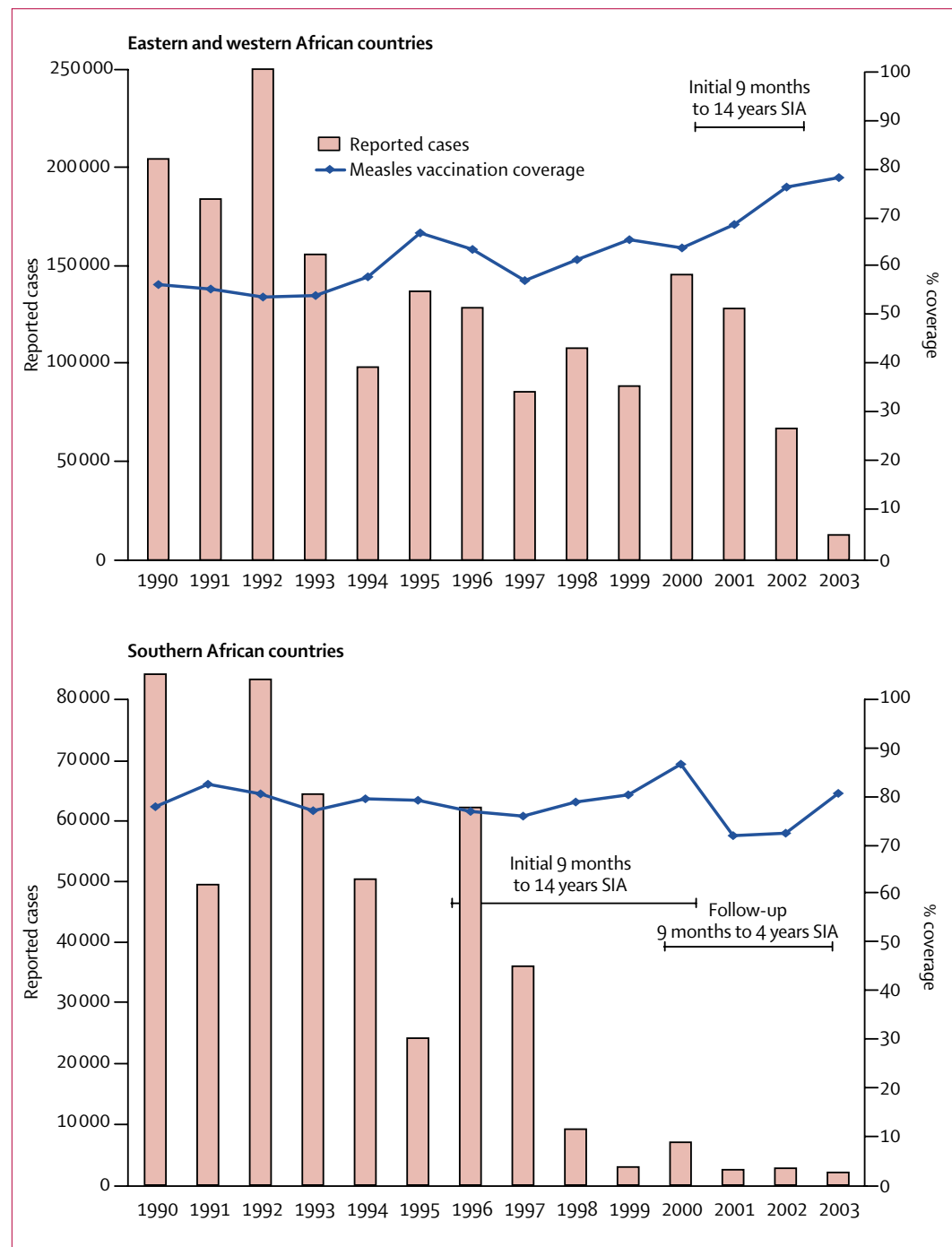

Figure: Numbers of reported measles cases and weighted average of routine measles vaccination coverage by year for two groups of countries

Note that the vertical scales for reported cases differ between the two plots.
These estimates were based on: the estimated number of surviving infants in 1998 in each country; a vaccine efficacy of 85\%; the 1998 national routine measles coverage percentage as reported to WHO; the assumption that all susceptible children would be infected with measles; and an estimated measles casefatality rate of $6.0 \%$ in west and central Africa, $2 \cdot 0-3 \cdot 0 \%$ in east African countries, and $0 \cdot 5-3 \cdot 0 \%$ in southern African countries. ${ }^{1}$

\section{Case-based surveillance}

After completing nationwide measles SIA, all countries started case-based reporting of suspected measles cases with laboratory confirmation. A case of suspected measles was defined as an illness characterised by rash, fever, and cough, coryza, or conjunctivitis, or any illness that a clinician suspected to be measles. Surveillance was classified as case-based if individual data, such as date of onset of rash, district of residence, age, and vaccination status, were collected on a case form or line list and sent to the national level. The serum sample was sent to the national measles laboratory to be tested for measles IgM antibody by Enzygnost (Dade-Behring, Marburg, Germany) diagnostic kits. The national measles laboratories are part of a WHO measles laboratory network that requires successful completion of a proficiency panel of serum samples each year. Measles case-based data are reported electronically to the WHO African Regional Office monthly. This office monitors surveillance reporting and publishes measles surveillance results and quality indicators in both bloc bulletins ${ }^{10}$ and regional feedback bulletins. ${ }^{11-13}$ After the SIA, most countries continued aggregate measles reporting in parallel with measles case-based reporting.

We used data from case-based surveillance to assign each country to one of three categories of measles transmission: very low; low intermittent; or moderate continuing. These categories were based on the proportion of suspected cases of measles with laboratory samples that were positive for measles IgM: less than $10 \%$ was classified as very low; $10-49 \%$ as low; and $50 \%$ or greater as moderate. This epidemiological profiling was based on nearly a decade of experience with surveillance after SIA in more than 40 countries in the Americas $^{4,14}$ and Africa. ${ }^{5}$

\section{Measles outbreaks after SIA}

After completing nationwide SIA, countries began to carry out measles outbreak investigations on a nationwide basis. The WHO African Regional Office has distributed guidelines to all African countries detailing recommended procedures for investigation of measles outbreaks, including village-level searches for additional suspected cases, laboratory confirmation, reporting, and analyses. In the African Region, a measles outbreak is defined as at least three laboratory-confirmed or five suspected measles cases in a district in any month that 
occurred more than 60 days after the SIA. All suspected and laboratory-confirmed cases are routinely mapped by district and examined for place and time clustering. Where outbreaks were detected, we examined the casebased information and attempted to define the extent and cause of each outbreak.

\section{Routine measles-vaccination coverage}

For the years 1990 to 2003, a weighted average of coverage with one dose of measles vaccine was calculated for the two groups of countries (southern Africa and eastern and western Africa) by use of the annual measles-vaccination coverage information that is officially reported to WHO.? The weighted average was calculated from the 1995 population estimate for each country from the United Nations Population Division. ${ }^{15}$

\section{Role of the funding source}

No funding source had any role in the study design; collection, analysis, or interpretation of data; or the writing of the report. The corresponding author had full access to all the data in the study and had final responsibility for the decision to submit the paper for publication.

\section{Results}

Between January, 2000, and June, 2003, 19 African countries carried out SIA and had at least 12 months of post-SIA measles-surveillance data (table 1). 12 countries in western and eastern African undertook SIA in children aged 9 months to 14 years (total children targeted 73.0 million), and seven southern African countries carried out follow-up SIA in children aged 9 months to 4 year (total children targeted 9.1 million). Five countries completed the SIA nationwide over 2 years (Benin, Cameroon, Ghana, Zambia, and Tanzania). Thus, the total number of children targeted in these SIA was 82.1 million. The reported measles vaccination coverage was $85 \%$ or higher for all SIA. The average SIA measles vaccination coverage for the six countries that did surveys was $97 \%$ (table 1 ).

In the 12 western and eastern African countries, the number of reported measles cases declined from $85000-250000$ during 1990-2001 to 12073 in 2003 (figure). In the seven southern African countries, the number of reported measles cases fell from 24 000-140 000 during 1990-97 to 2081-7057 per year from 1999 to 2003 (figure). The average proportional decrease in reported measles cases was $89 \%$ for the 12 eastern and western African countries and $91 \%$ for all 19 countries (table 2). Three countries had an average decline of less than $70 \%$. The low percentage decreases for Burkina Faso (67\%) and Namibia (65\%) were probably due to measles outbreaks. The low percentage decrease for Botswana (64\%) was probably due to misreporting of rubella cases as measles cases in 2000; of

\begin{tabular}{|c|c|c|c|c|c|}
\hline Country & $\begin{array}{l}\text { Estimated nationwide } \\
\text { number of deaths } \\
\text { before SIA* }\end{array}$ & $\begin{array}{l}\text { Average number of } \\
\text { reported cases per year } \\
\text { before SIA } \dagger\end{array}$ & $\begin{array}{l}\text { Number of reported } \\
\text { cases per year } \\
\text { after SIA } \ddagger\end{array}$ & $\begin{array}{l}\text { Percentage decrease } \\
\text { in number of cases } \S\end{array}$ & $\begin{array}{l}\text { Number of deaths } \\
\text { averted per yearqा }\end{array}$ \\
\hline \multicolumn{6}{|c|}{ Countries with initial SIA in children aged 9 months to 14 years, December, 2001, to June, 2003} \\
\hline Benin & 2990 & 4051 & 217 & 95 & 2830 \\
\hline Burkina Faso $\neq$ & 15626 & 7147 & 2345 & 67 & 10499 \\
\hline Burundi & 4472 & 8022 & 224 & 97 & 4347 \\
\hline Cameroon & 9398 & 13260 & 899 & 93 & 8761 \\
\hline Ghana & 12899 & 24583 & 1939 & 92 & 11882 \\
\hline Kenya & 9669 & 9529 & 65 & 99 & 9603 \\
\hline Malif & 11014 & 5568 & 475 & 91 & 10075 \\
\hline Rwanda\|l| & 2448 & 2425 & 52 & 98 & 2396 \\
\hline Senegal & 6855 & 9275 & 1638 & 82 & 5644 \\
\hline Tanzania & 13955 & 10078 & 1673 & 83 & 11638 \\
\hline Togo & 5475 & 2082 & 329 & 84 & 4610 \\
\hline Zambial| & 3781 & 17609 & 2963 & 83 & 3145 \\
\hline Subtotal & 98582 & 113629 & 12819 & 89 & 85430 \\
\hline \multicolumn{6}{|c|}{ Southern African countries with follow-up campaigns in children aged 9 months to 4 years, 2000-03 } \\
\hline Botswana & 62 & 1767 & 636 & 64 & 40 \\
\hline Lesotho & 126 & 1246 & 73 & 94 & 119 \\
\hline Malawi & 2686 & 9581 & 173 & 98 & 2637 \\
\hline Namibia & 96 & 2515 & 879 & 65 & 62 \\
\hline South Africa & 1034 & 11118 & 112 & 99 & 1024 \\
\hline Swaziland & 55 & 2151 & 112 & 95 & 52 \\
\hline Zimbabwe & 704 & 22592 & 817 & 96 & 679 \\
\hline Subtotal & 4763 & 50967 & 2800 & 95 & 4613 \\
\hline Grand total & 103345 & 164596 & 15619 & 91 & 90043 \\
\hline $\begin{array}{l}\text { *Based on data } \mathrm{fr} \\
\text { Faso had } 2 \text { years } \\
\text { multiplied by per }\end{array}$ & $\begin{array}{l}\text { ge for } 1996-2001 \text { in the } 1 \\
\text { (2002, 2003), which were a } \\
\text { in cases. ||Rwanda post-SI }\end{array}$ & $\begin{array}{l}\text { tern and western African co } \\
\text { yed. SAverage number befor } \\
\text { a were from March, 2003, to }\end{array}$ & $\begin{array}{l}\text { es, and for } 1990-95 \text { in } \\
\text { minus number after SI } \\
\text { uary, 2004; Zambia dat }\end{array}$ & $\begin{array}{l}\text { thern African countries. } \ddagger 2 \\
\text { ed by pre-SIA average, } \times 1 \\
\text { from July, } 2003 \text {, to June, } 2\end{array}$ & $\begin{array}{l}\text { 3; Mali, Togo, and Burki } \\
\text { IPre-SIA deaths }\end{array}$ \\
\hline
\end{tabular}


210 blood samples tested during that year, 170 (81\%) were positive for rubella IgM and none for measles IgM. ${ }^{16}$

The total estimated number of annual deaths averted in 2003 was 90 043: 85430 for the 12 eastern and western African countries and 4613 for the southern African countries. The pre-SIA baseline estimate of the annual number of measles deaths for all countries in the African Region in 1998 was 454 000. Therefore, for the African Region as a whole, the estimated proportional decrease in annual measles deaths was 20\% (90 043 divided by 454000 ) resulting from control activities in these 19 countries from 2000 to June, 2003.

In 2002-03, the proportion of suspected measles cases that were confirmed to be positive for measles IgM ranged from $2 \%$ in Zambia to $74 \%$ in Burkina Faso (table 3). Among the 11 western and eastern African countries other than Burkina Faso, 10\% (588 of 5929) of samples tested were positive for measles IgM antibody. Among the 12 western and eastern African countries, six countries had very low measles transmission (less than $10 \%$ of the laboratory samples positive for measles IgM), five had low measles transmission profiles, and one country (Burkina Faso) had moderate transmission. Among the seven southern African countries, five had very low transmission, one had low transmission, and one (Namibia) had moderate transmission (table 3). In southern Africa, 643 (10\%) of 6619 samples tested were positive for measles IgM.
In 2002-03, 16 measles outbreaks occurred 60 days or longer after an SIA (table 4). In 11 outbreaks there were more than ten cases. Five of the 11 outbreaks were in areas bordering countries that had not undertaken SIA (southern Mali bordering Guinea, Cameroon bordering Nigeria [three outbreaks], and Mpumalanga Province, South Africa, bordering Mozambique). One outbreak occurred mainly among individuals aged 15 years and older among nomads in northern Mali. Two outbreaks occurred in island populations that had very low coverage during the catch-up campaign (Pemba island, Tanzania, and Bonassama district, Cameroon).

In Burkina Faso, the number of reported cases was only partly reduced after SIA (1744 in 2002 and 2946 in 2003). Burkina Faso was the only country of 19 countries that had measles transmission during the entire period after the initial SIA as shown by casebased and aggregate surveillance data. An outbreak investigation showed that the continuing transmission was related to a large number of unvaccinated children returning from Côte d'Ivoire during a time of political turmoil. ${ }^{17}$

In Namibia, after 4 years of no measles circulation, an outbreak (1218 cases and 13 reported measles deaths) continued for 18 months during 2002-03. In Zimbabwe, an outbreak with 80 cases and 20 reported deaths occurred 4 years after the initial SIA and after the first follow-up SIA. The Zimbabwe outbreak was restricted and occurred near the border with Mozambique, which

\begin{tabular}{|c|c|c|c|c|c|}
\hline Country & Year & $\begin{array}{l}\text { Number of reported } \\
\text { measles cases* }\end{array}$ & $\begin{array}{l}\text { Number of cases with } \\
\text { laboratory samples taken } \\
\text { and results available }\end{array}$ & $\begin{array}{l}\text { Positive for } \\
\text { measles IgM }\end{array}$ & $\begin{array}{l}\text { Epidemiological } \\
\text { profile of measles } \\
\text { transmission }\end{array}$ \\
\hline \multicolumn{6}{|c|}{ Countries with initial SIA in children aged 9 months to 14 years, December, 2001, to June, 2003} \\
\hline \multirow[t]{2}{*}{ Benin } & 2002 & 76 & 70 (92\%) & $22(31 \%)$ & Low \\
\hline & 2003 & 215 & $211(98 \%)$ & $58(27 \%)$ & Low \\
\hline \multirow[t]{2}{*}{ Burkina Faso } & 2002 & 1337 & $1029(77 \%)$ & 709 (69\%) & Moderate \\
\hline & 2003 & 6315 & $2682(42 \%)$ & 1997 (74\%) & Moderate \\
\hline Burundi & 2003 & 89 & 79 (89\%) & $3(4 \%)$ & Very low \\
\hline \multirow[t]{2}{*}{ Cameroon } & 2002 & 33 & $33(100 \%)$ & $5(15 \%)$ & Low \\
\hline & 2003 & 878 & $878(100 \%)$ & $215(24 \%)$ & Low \\
\hline \multirow[t]{2}{*}{ Ghana† } & 2002 & 147 & $85(58 \%)$ & $6(7 \%)$ & Very low \\
\hline & 2003 & 1487 & $1148(77 \%)$ & $46(4 \%)$ & Very low \\
\hline Kenya & 2003 & 1791 & 1736 (97\%) & $59(3 \%)$ & Very low \\
\hline \multirow[t]{2}{*}{ Mali } & 2002 & 533 & $63(12 \%)$ & $22(35 \%)$ & Low \\
\hline & 2003 & 226 & $130(58 \%)$ & $61(47 \%)$ & Low \\
\hline Rwanda & 2003 & 48 & $47(98 \%)$ & $7(15 \%)$ & Low \\
\hline Senegal & 2003 & 348 & $109(31 \%)$ & $23(21 \%)$ & Low \\
\hline Tanzania & 2003 & 665 & $240(36 \%)$ & $17(7 \%)$ & Very low \\
\hline \multirow[t]{2}{*}{ Togo } & 2002 & 333 & $250(75 \%)$ & $23(9 \%)$ & Very low \\
\hline & 2003 & 275 & 250 (91\%) & $11(4 \%)$ & Very low \\
\hline Zambia & 2003 & 2315 & $600(26 \%)$ & $10(2 \%)$ & Very low \\
\hline \multicolumn{6}{|c|}{ Seven southern African elimination countries } \\
\hline \multirow[t]{2}{*}{ Five countriesł } & 2002 & 1159 & $1015(88 \%)$ & $30(3 \%)$ & Very low \\
\hline & 2003 & 4780 & $4535(95 \%)$ & $233(5 \%)$ & Very low \\
\hline Zimbabwe & 2003 & 489 & $489(100 \%)$ & $59(12 \%)$ & Low \\
\hline \multirow[t]{2}{*}{ Namibia } & 2002 & 646 & $422(65 \%)$ & $300(71 \%)$ & Moderate \\
\hline & 2003 & 163 & $158(97 \%)$ & $21(13 \%)$ & Low \\
\hline
\end{tabular}




\begin{tabular}{|c|c|c|c|c|c|}
\hline Country & Location & Year & Number of cases & $\begin{array}{l}\text { Duration of outbreak, } \\
\text { months }\end{array}$ & Comment \\
\hline \multirow[t]{2}{*}{ Benin } & Tchaourou district & 2002 & 10 & 2 & \\
\hline & D'Dali district & 2002 & 5 & 2 & \\
\hline Burkina Faso & Many districts & 2002 and 2003 & 1744 and 6315 & $>24$ & $\begin{array}{l}\text { Widespread transmission after SIA, many } \\
\text { cases just returning from Côte d'Ivoire }\end{array}$ \\
\hline \multirow[t]{4}{*}{ Cameroon } & Bonassama district & 2002 & 38 & 2 & Low SIA coverage, island \\
\hline & Mogode district & 2002 & 5 & 2 & Cases mainly from Nigeria \\
\hline & Garoua rural district & 2002 & 10 & 2 & Cases mainly from Nigeria \\
\hline & Touboro district & 2002 & 6 & 2 & Cases mainly from Nigeria \\
\hline \multirow[t]{4}{*}{ Mali } & Tomboctu & 2002 & 39 & 1 & Mostly nomads, $>15$ years old \\
\hline & Southern & 2002 & 36 & 1 & \\
\hline & Sikasso district & 2003 & 35 & 3 & \\
\hline & Goa district & 2003 & 38 & 2 & \\
\hline Namibia & Most of country & 2002-03 & 1218 & 18 & Long-lasting transmission ( $>12$ months) \\
\hline \multirow[t]{2}{*}{ South Africa } & Gauteng province, & 2003 & 102 & 4 & $\begin{array}{l}\text { Limited outbreak, } 1 \text { death in child with } \\
\text { HIV and tuberculosis }\end{array}$ \\
\hline & $\begin{array}{l}\text { Region A, B } \\
\text { Nkomazi subdistrict, } \\
\text { Mpumalanga Province }\end{array}$ & 2003 & 35 & 5 & $\begin{array}{l}\text { Thought to be imported from } \\
\text { Mozambique }\end{array}$ \\
\hline Tanzania & Pemba island & 2003 & 131 & 1 & Very low SIA coverage (68\%) \\
\hline Zimbabwe & Manicaland Province & 2003 & 80 & 3 & $\begin{array}{l}20 \text { deaths, religious refusers, near } \\
\text { Mozambique border }\end{array}$ \\
\hline
\end{tabular}

is the only country in southern Africa that has not undertaken measles SIA.

In 2000 , nine of the 12 countries that undertook initial SIA in 2001-03 reported routine measles vaccination coverage of less than $80 \%$ (table 1). In 2003, reported measles vaccination coverage had increased by $10 \%$ or more in all of these nine countries. In the 12 eastern and western African countries, the weighted average of routine measles vaccination coverage increased from $64 \%$ in 2000 to $78 \%$ in 2003 (figure). In the seven southern African countries, the weighted average of routine measles vaccination coverage was stable at $78-83 \%$ before the SIA (1990-95) then increased to $87 \%$ in 2000 during the period of initial SIA. In 2001 and 2002 , routine coverage decreased to $72 \%$ and $73 \%$, respectively, largely owing to lower reported coverage in Namibia, Swaziland, and Zimbabwe. In 2003, reported coverage was $81 \%$.

\section{Discussion}

In 19 of 46 countries in the African Region, analyses of three types of surveillance data indicate a substantial reduction in the number of measles cases after SIA. On the basis of aggregate surveillance data from these 19 countries, there was a $91 \%$ reduction in the number of reported measles cases after SIA targeting of a wide age range. Furthermore, the low proportion of suspected measles cases confirmed as true cases and the infrequent occurrence of outbreaks are consistent with a striking reduction in measles transmission immediately after the SIA. Extrapolating these findings to the effect on measles deaths, we estimated a $20 \%$ reduction in the annual number of measles deaths in the African Region as a whole in 2003. This estimated decline represents substantial progress towards the Regional goal of nearzero measles deaths and the worldwide goal of $50 \%$ reduction in measles deaths by 2005 .

To allow assessment of progress toward these mortality reduction goals, we made a crucial assumption that the proportional reduction in measles deaths was equal to the proportional reduction in measles cases. We believe that this assumption was realistic for the following reasons. First, after initial SIA in 13 of the 19 countries, the decline in reported measles deaths closely matched the decline in reported measles cases. Second, case-based surveillance after the SIA confirmed that measles transmission was low or very low in 17 of the 19 countries and outbreaks that did occur were small (five to 130 cases). At high SIA coverage and with such low rates of transmission, to conceive of a plausible scenario in which the death reduction would not approximate the case reduction is difficult. Third, the proportional decline in routinely reported measles cases could underestimate the true reduction in mortality after SIA, because only $10 \%$ of reported measles cases were confirmed as measles after SIA.

We used available surveillance data to measure the effect of the programme. Common criticisms of surveillance data include under-reporting and variable quality in some areas. Nevertheless, we found striking decreases in aggregate reported measles cases in all 19 countries immediately after implementation of wideage-range SIA. The quality of measles case-based surveillance is monitored by the WHO African Regional Office with two indicators: the rate of suspected measles cases with blood samples collected (target at least $1 \cdot 0$ per 100000 total population) and the proportion of districts with at least one suspected measles case with a blood 
sample (target at least $80 \%$ ). All countries reached the minimum rate of suspected measles cases with blood samples collected in both $2003^{11}$ and 2004 (unpublished WHO African Regional Office bulletin). The proportion of districts with at least one suspected measles case with a blood sample reached at least $50 \%$ in 17 of 19 countries in 2003 and in 16 of 19 countries in 2004.

The evidence of substantial declines in measles burden is lent further support from all three overlapping surveillance components pointing to the same conclusion. Routine surveillance showed a decline of more than $80 \%$ in reported measles cases in 16 of 19 countries. Case-based measles surveillance showed that only $10 \%$ of more than 12000 blood samples tested were positive for measles IgM (with Burkina Faso excluded). Outbreak surveillance showed no continuing transmission except in Namibia and Burkina Faso.

In the Americas ${ }^{4}$ and southern Africa, ${ }^{5}$ high-quality SIA have resulted in interruption of endemic measles transmission for 3 years or longer depending on the preexisting routine vaccination coverage. If we assume that the effect of SIA lasted 4 years when routine measles coverage was $80 \%$ or higher and 3 years if routine measles coverage was less than $80 \%$, the total projected number of deaths that would be averted over the next 3-4 years is 304 212: 285783 in the 12 eastern and western African countries and 18429 in the seven southern African countries. These projections provide a rough estimate of the public-health impact of accelerated measles control efforts in the African Region over the medium term.

The advantage of estimating mortality reduction on the basis of measured declines in reported disease (over a model based on vaccination coverage) is shown by the examples of Burkina Faso and Namibia. These two countries had episodes of continuous measles transmission lasting longer than 12 months despite reported measles SIA coverage similar to other countries in the region; in Burkina Faso, post-SIA coverage was verified by a standard cluster survey (table 1). Yet measles surveillance detected unexpected increases in measles cases, which led to investigations and responses. The unexpected increase in measles cases came immediately after SIA in Burkina Faso and after the first follow-up SIA in Namibia. The discrepancy between a coverageonly model approach and a disease-measurement approach might become magnified once more countries in Africa are undertaking follow-up campaigns and large countries with low routine vaccination coverage such as Ethiopia and the Democratic Republic of Congo complete their initial catch-up SIA.

The mostly likely explanation for the observed sudden reduction in the number of cases after SIA is the ability of these activities to increase population immunity rapidly and thereby prevent measles transmission. Routine measles vaccination coverage increased 14\% over a 3-year period in the 12 eastern and western African countries but remained unchanged in the seven southern African countries. A gradual increase in routine immunisation measles coverage will decrease accumulation of susceptible children and might allow countries to increase the time between follow-up SIA from 3 years to $4-5$ years.

Our study had several limitations. Because measles deaths are not routinely reported to WHO, we relied on available WHO estimates for the number of deaths before the SIA. For most non-southern African countries, we had surveillance data for only 1 year after SIA. However, data from southern African countries showed an effect that has lasted 4-8 years, as long as regular follow-up SIA are undertaken. In addition, we did not have information on changes in case management (eg, use of vitamin A) or changes in age distribution of patients with reported measles, and we could not assess changes in surveillance quality of the routine (aggregate) surveillance system. A substantial decline in measles transmission might result in a shift in the age distribution of measles to older individuals, in whom the case-fatality rate is lower, thereby resulting in an underestimate of the reduction in measles burden.

There is active debate about the positive and negative effects of mass vaccination campaigns on routine primary-health-care services. ${ }^{18,19}$ On the positive side, mass campaigns, if well planned and executed, achieve equity by reaching children who are missed by routine services and result in protection of children who are vulnerable (eg, owing to HIV infection) or unvaccinated by reducing transmission to very low rates. Benefits of campaigns can be increased by addition of interventions such as oral poliovirus vaccine, vitamin A, insecticidetreated bednets, and anthelmintics and through new equipment (eg, for the cold chain) and training (eg, for injection safety) put in place for the campaign. On the negative side, mass campaigns divert staff and resources such as vehicles that were intended for other primarycare services. Furthermore, if training and logistics are inadequate, they can lead to unsafe injection practices, difficulties with waste disposal, and adverse events due to human error. Measles SIA are done only once every 3-4 years and, despite their disruption of routine health services, they can be highly cost-effective disease-control activities in settings where country infrastructure is weak. Although more data are needed, the available evidence suggests that countries can both complete highquality SIA and increase routine coverage.

SIA in children aged 9 months to 14 years have been superior to those in children aged 9 months to 4 years during the past 5 years in most African settings. ${ }^{1}$ The number of deaths averted is three times higher with SIA in children aged 9 months to 14 years than with those in the narrower age range. In countries with moderate to high routine coverage, SIA in children aged 9 months to 4 years lowered the number of measles cases by half for 
1-2 years; ${ }^{1}$ SIA in children aged 9 months to 14 years lower the number of measles deaths to near zero for nearly twice as long (3-4 years). We hypothesise that reduction of transmission to near zero is the reason for the better effect of the wider-age-range SIA. With no measles transmission, all measles vaccinations (even those given at ages 1-4 years) are given before infection, no measles cases occur before the time of vaccination at 9 months, older children do not act as reservoirs to infect younger non-immune children, and children who are missed by the routine vaccination programme or who have experienced vaccine failure are not infected.

The total donor costs for the SIA in the 19 countries were US\$68.1 million (Measles Initiative and WHO African Regional Office, unpublished data). From the donor's perspective, the cost per child targeted was US $\$ 0.83$ and cost per death averted was US\$224. More detailed economic studies are needed for assessment of the costs and benefits of accelerated measles-control strategies in the African setting, for example from societal and government perspectives.

The goal of the African Regional measles plan of action is to sustain measles mortality at near zero. The southern African countries showed sustainable measles control, having maintained the striking reduction in measles cases for 5 years or longer (figure). The challenges for the future are to increase routine measles immunisation coverage to more than $80 \%$ in every district so that follow-up SIA targeting children aged 9 months to 4 years would be required only every 4 years, to identify resources to undertake regular follow-up SIA to sustain the number of measles deaths near zero, and to maintain continuous monitoring and feedback through surveillance. The cost of follow-up SIA every 3-4 years for all countries of the African Region (until 2010) is estimated at US\$30-40 million per year (annual WHO African Regional Office measles plan of work, 2003, unpublished).

During the past 5 years, a partnership has been formed between ministries of health, non-governmental organisations, and civil society that has been able to ensure high equitable coverage with live-saving vaccines through SIA while increasing coverage of routine services. The immunisation programme has also established an information system to measure coverage and impact continuously at the district level. The potential exists to use similar partnerships, programme infrastructure, and information systems to reach nationwide high coverage for other child survival interventions (eg, insecticide-treated bednets ${ }^{20}$ ).

Contributors

M Otten, R Kezaala, A Fall, B Masresha, R Martin, R Eggers, R Biellik, M Grabowsky, J-M Okwo-Bele, and D Nshimirimana helped with designing and implementing data-collection systems and the measles control programme. P Strebel and L Cairns helped write the report. All the authors critically contributed to the final preparation of the report. The views expressed are solely those of the authors and are not those of the WHO.
Conflict of interest statement

We declare that we have no conflict of interest.

\section{Acknowledgments}

We thank all the Ministry of Health workers in Africa who carried out surveillance and supplemental immunisations, and the WHO African Region immunisation and surveillance staff who collaborated with Ministries of Health on surveillance and routine and supplemental immunisation.

References

Otten MW Jr, Okwo-Bele JM, Kezaala R, Biellik R, Eggers R, Nshimirimana D. Impact of alternative approaches to accelerated measles control: experience in the African region, 1996-2002. J Infect Dis 2003; 187 (suppl 1): S36-43.

2 WHO. Progress in reducing global measles deaths: 1999-2002. Wkly Epidemiol Rec 2004; 79: 20-21.

3 WHO. World health report 2001 statistical annex. Available at: http://www.who.int/whr/2001/annex/en/. Annex Table 2: Deaths by cause, sex and mortality stratum in WHO Regions, estimates for 2000. Annex2_en.pdf, p 145 (accessed March 9, 2005)

4 de Quadros CA, Hersh BS, Nogueira AC, Carrasco PA da Silveira CM. Measles eradication: experience in the Americas. Bull World Health Organ 1998; 76 (suppl 2): 47-52.

5 Biellik R, Madema S, Taole A, et al. First 5 years of measles elimination in southern Africa: 1996-2000. Lancet 2002; 359 . 1564-68.

WHO, United Nations Children's Fund. Joint statement on strategies to reduce measles mortality. WHO/V\&B/01.40, UNICEF/PD/Measles/01. 2001.

7 WHO Africa Regional Office. http://www.who.int/vaccinessurveillance/StatsAndGraphs.htm (accessed Aug 1, 2004).

8 Centers for Disease Control and Prevention. Measles mortality reduction, West Africa, 1996-2002. MMWR Morb Mortal Wkly Rep 2004; 53: 28-30

Centers for Disease Control and Prevention. Progress in measles control, Zambia, 1999-2004. MMWR Morb Mortal Wkly Rep 2005; 54: 581-84.

10 WHO Africa Regional Office. http://www.afro.who.int/csr/ids/ bulletins/index.html (accessed March 9, 2005).

11 WHO Africa Regional Office. http://www.afro.who.int/measles/ feedback-tables/ (accessed March 9, 2005).

12 WHO Africa Regional Office. http://www.afro.who.int/ddc/vpd/ bulletins/2004/index.html (accessed March 9, 2005).

13 WHO Africa Regional Office. http://www.afro.who.int/csr/ids/ bulletins/index.html (accessed March 9, 2005).

14 Hersh BS, Tambini G, Nogueira AC, Carrasco P, de Quadros CA Review of regional measles surveillance data in the Americas, 1996-99. Lancet 2000; 355: 1943-48.

15 http://esa.un.org/unpp/p2k0data.asp (accessed Feb 23, 2005).

16 http://www.afro.who.int/csr/ids/bulletins/2000.html, Southern Bloc bulletin dec2000.pdf (accessed Aug 30, 2004).

17 Yaméogo RK, Perry RT, Yaméogo A, et al. Risk factors for measles after a mass vaccination campaign, Burkina Faso, 2002. Int J Epidemiol 2005; 34: 556-64.

18 Dietz V, Cutts F. The use of mass campaigns in the expanded program on immunization: a review of reported advantages and disadvantages. Int J Health Serv 1997; 27: 767-90.

19 Loevinsohn B, Aylward B, Steinglass R, Ogden E, Goodman T, Melgaard B. Impact of targeted programs on health systems: a case study of the Polio Eradication Initiative. Am J Public Health 2002 92: 19-23.

20 http:/www.ifrc.org/docs/news/pr04/8504.asp (accessed March 8 , 2005) 